\title{
ПАРТИСИПАТИВНОЕ ПРОЕКТИРОВАНИЕ КОМПЛЕКСНОГО РАЗВИТИЯ УЧРЕЖДЕНИЯ СРЕДНЕГО ОБРАЗОВАНИЯ: ТЕОРЕТИКО-СОЦИОЛОГИЧЕСКИЙ АНАЛИЗ
}

\author{
Алешина Елена Викторовна, \\ school13@noyabrsk.yanao.ru \\ Средняя общеобразовательная школа № 13 \\ с углубленным изучением предметов эстетического цикла, \\ Россия, 629803, г. Ноябрьск, ул. Высоцкого, 40а
}

\begin{abstract}
Алешина Елена Викторовна, заместитель директора средней общеобразовательной школы № 13 с углубленным изучением предметов эстетического цикла.

В статье рассматриваются понятие, специфика и значение проектирования в комплексном развитии учреждений среднего образования. Автор осуществляет анализ с позиций социологической теории, в дискурсе социологии управления. Раскрывается понятие проекта и проектирования как формализованной деятельности по определению проблематики и планирования ряда мероприятий, направленных на решение проблем. Кратко описывается типология проектов, выделяются их формы (услуга, мероприятие), а также характер (инновационные, поддерживающие). В краткой форме изложен генезис идей проектирования в рамках социологической науки в русле воззрений О. Конта, Р. Парка, Э. Берджесса, Т. Лукмана. Обозначены современные тенденции социологического анализа проектирования. Обосновывается, что партисипативное проектирование может быть направлено на формирование активной образовательно-воспитательной среды развития в учреждении среднего образования. Такая среда детерминирует рост качества предоставления образовательных услуг и их результатов в ходе проведения особого рода сконфигурированных мероприятий, с участием не только членов администрации, но и всех заинтересованных участников образовательных отношений - школьников, родителей, СОНКО и т. д. Культивируется и раскрывается принци партисипативности в процессе проектирования. Сами акторы участвуют в проектировании и реализации проекта, в котором они заинтересованы. В результате эффективность такого продукта возрастает в разы. А сам проект становится катализатором формирования командных взаимоотношений внутри и между различными сообществами (управление, учителя, ученики, родители и пр.). Вывод: партисипативное проектирование обладает потенциалом образования особого типа среды развития в рамках учреждения среднего образования.
\end{abstract}

Ключевые слова: Проект, социальное проектирование, партисипативный проект, активная образовательно-воспитательная среда развития.

\section{Введение}

Комплексное развитие учреждения среднего образования может быть операционализировано в рамках такого комплексного показателя, как качество образования. Социальное проектирование показало свою эффективность в частности в системе среднего образования. Поскольку создание и реализация проектов позволяют в эффективном формате решать конкретные задачи, также можно просчитать объем требуемых ресурсов и т. д. В рамках школы особое значение приобретает формирование активной образовательно-воспитательной среды развития, т. к. она является совокупностью внешних и 
внутренних условий, детерминирующих рост эффективности школ в части большего числа показателей «качества образования» (успеваемость, воспитанность, активность участия в проектной деятельности, количество успешных поступлений в топовые вузы страны, призовые места на олимпиадах, количество медалистов и в целом имидж учреждения среднего образования и т. д). Однако «воспитательная» эффективность социального проекта в школе (его способность формировать «ту самую» «благодатную», «волшебную», «чудесную» среду) обусловлена его потенциалом выявлять и учитывать интересы широкого круга заинтересованных лиц - представителей таких групповых акторов, как школьная администрация, педагогический коллектив, родительское и ученическое сообщество и иных акторов. Очевидно, успешный социальный проект в школе не только выражает интересы акторов, но и вовлекает их в совместную деятельность в собственных интересах. Такой проект называется партисипативным (от англ. participation - «вовлечение, включение»). О таких проектах пойдет речь в статье.

\section{Результаты исследования}

Партисипативное проектирование включает в себя понятия проектирования и партисипации. Поскольку управление, как особый вид социального взаимодействия, отличается нацеленностью на выработку управленческого решения, в данном случае системная реализация социального управления предполагает четкое целеполагание, заранее предопределенную логику, программу, ожидаемый комплексный социальный результат и т. д. Также особое значение в школе, наряду с выработкой управленческих решений, приобретают доведение их до исполнителей и обеспечение должного исполнения.

В таком случае суть системного социального управления оказывается тесно связанной с социальным проектированием, проектным процессом вообще и может быть кратко представлена в рамках следующей схемы.

Социальное управление заключается в способности субъекта управления вырабатывать и реализовывать проекты деятельности, привлекая широкий круг субъектов управления и создавая при этом все необходимые условия.

«Проект - комплекс взаимосвязанных мероприятий, предназначенных для достижения в течение заданного периода времени и при установленном бюджете поставленных задач с четкими целями» [1]. Проектное управление «подразумевает разработку календарного плана выполнения мероприятий, определение ролей, назначение руководителя и группы, а впоследствии - реализацию работ по проекту с использованием различных технологий, например проектного финансирования» [2, с. 78].

Проектирование развития в социальной науке имеет богатую традицию. Идеи проектирования активно развивал и О. Конт, ставя задачи проектирования будущего состояния общества и непосредственной подготовки на основании этого социальных реформ. Р. Парк, Э. Берджесс включили понятие проекта в концептуальное ядро своих социологических концепций. Б. ван Штинберген вообще предложил выделить отдельный раздел социологии проектирования - design sociology, как «место встречи» макросоциологического и проектного понимания развития социальных взаимоотношений. Такая социология неизбежно станет «участником формулирования и обоснования социальных целей» [3] в современном обществе. Социолог становится социальным архитектором, реализующим инновации в общественном развитии, применяя социологический инструментарий. Возможно, речь идет о социальном конструировании, инженерии? Автор уверен, что да. 
Социальное конструирование реальности (П. Бергер и Т. Лукман) развивает подобные идеи именно с позиции социологического подхода, предлагая додумывание, придумывание, переструктурирование окружающего мира. Социальное конструирование не произвольно и осуществляется в рамках заданной культуры, системы общественных отношений, ценностей и норм конкретного сообщества людей и т. д.

В контексте социального дизайна, социальной инженерии и социального конструирования проектирование представляется как особого рода деятельность по формированию социальным актором целеустремленной системы действий. Важная особенность заключается в том, что действие ограничивается «рамками» проекта: локализовано по месту, времени и ресурсам.

Таким образом, можно сказать, что социальный проект «является инструментом системных социальных изменений» [4], основывающийся на природном человеческом стремлении творить, созидать, преобразовывать, развивать и развиваться - создавать, формировать, конструировать реальность.

Поскольку предметом социального проектирования выступает практический результат по созданию чего-то нового, модернизации уже существующего, или сохранению уже имеющегося в изменившейся социальной среде, формы реализации социального проекта весьма разнообразны. К числу наиболее распространенных относятся: вещь, услуга, организация, мероприятие/комплекс мероприятий, проект закона.

К числу форм, которые актуальны в контексте предмета данного исследования можно отнести услугу (результат деятельности по удовлетворению той или иной социальной потребности) и мероприятие (совокупность действий, организованных и реализуемых в рамках реализации определенной цели).

Поскольку проект создается для реализации социальных изменений, в зависимости от характера можно выделить инновационные (реализация инноваций, то есть чего-то принципиально нового), и поддерживающие (обновление с использованием уже проработанных инструментов, с сохранением основ, традиций и т. д.).

Однако отметим, что также распространены проекты не поддерживающие и не инновационные, а имеющие целью создание, например, уже известных реализованных ранее услуг, проведение мероприятий и т. д., однако в новых условиях, для новых участников.

Многие социальные проекты в образовании не являются прибыльными, однако их социальная значимость, безусловно, высока. Поэтому органы государственной власти и местного самоуправления поддерживают такие проекты финансово. Однако в некоторых случаях возможен вариант с привлечением спонсоров, а также ряда СОНКО (в рамках реализации программ государственного субсидирования некоммерческим организациям), государственно-частного-партнерства, фандрайзинга и т. д. У автора есть положительный опыт использования ресурса автономной некоммерческой организации «Региональный центр развития талантов "УникУм"».

Далее рассмотрим субъектно-ориентированный подход к процессу социального проектирования как важную методологическую особенность, исходя из предмета исследования данной диссертации.

Фокус внимания этого подхода обращен в сторону автора и инициатора социального проекта, социального актора - индивидуального или группового (R. Akoff, D.K. Njeru, S. Alvarez, S. Arnstein, L. S. Clark, M. T. Dang, A. Amos, E. Daniel, C. Dayer, B. Guy, J. Kelly, A. Musawir, M. Sarrica, S. S. Visser, В. Луков, Л. П. Ефимова, Е.А. Туринцева, М.Н. Филатова, Т.З. Адамьянц, Ю.А. Никифоров, Л.В. Нургалеева и др.). 
В практике партисипативного подхода к планированию и проектированию распространены термины «steakholders» [5], «perticipatore community» [6], «круг заинтересованных лиц» [7] и «вовлеченные сообщества» [8], «активные со-участники» [9].

По мнению автора, такой подход применим к практике управления системного учреждения среднего образования, поскольку в данном случае увеличивается акцент внимания на социальных акторах проектирования, которые являются главными фактическими интересантами реализации проекта. Конкретный «школьный» проект призван изменить их реальность, решить какую-то актуальную проблему, и акторы становятся соучастниками создания, реализации и контроля над реализацией данного социального проекта. Главный плюс в применении на практике такого проблемно ориентированного, «вовлекающего», социально активного аспекта методологии проектирования заключается в существенном ее усовершенствовании с точки зрения системы управления средним образованием.

Очевидно, что применяя субъект-ориентированный подход к социальному проектированию, а также с учетом принципов системного анализа, мы должны закрепить в тексте такие понятия, как «партисипация», «партисипативный проект».

«Партисипация» обозначает процесс, социальное свойство и в русскоязычных источниках применяется в значениях: «принятие участия», «вовлечение», «соучастие», «причастность», «приобщение», «включение». Встречаются термины «партисипативного», «партисипативного», «партисипаторного» - все они, по мнению автора, - синонимичны. Поскольку исходят из одного корня.

Однако нередко термин «партисипация» соотносится с категориями «участие», «соучастие», «вовлеченность». Большинством ученых термины «партисипация» и «партисипативность» разводятся. Так, партисипативность рассматривается в качестве организационной идеи, принципа управления организацией; как управленческий феномен, заключающийся в участии рядовых сотрудников в управленческих процессах; в виде метода мотивации и организации членов коллектива; как средство повышения качества управленческих решений в организации и т. д.

Как отмечает К. Дэйер, под партисипацией в строгом смысле слова следует понимать «вовлечение людей в деятельность (управленческую - Е.А.) существующих организаций, как формальных, так и неформальных» [10].

По мнению А.А. Деникина «привлечение подходов, ориентированных на нужды и интересы людей означает, что человек сам становится ответственен за своё будущее» [11, с. 52].

Таким образом, партисипация есть «взаимодействие между людьми, когда каждый человек, проявляя активность, дополняет результаты, полученные в процессе взаимообмена» [11, 52].

По мнению Н.С. Шкитиной «партисипация является антропологической константой, присущей человеческому сообществу, она возникает и функционирует в социальных группах, где присутствуют субъект-субъектные отношения, она предполагает установление делового сотрудничества, равноправия в принятии решений» [12, с. 148]. При таком подходе, очевидно, в процесс проектирования максимально включается рядовой член общества, при этом повышается его вовлеченность и личная заинтересованность в ходе реализации проекта, а также в итоговых результатах проектной деятельности.

Нередко в контексте партисипативного подхода интерпретируется самоуправление. Так, С. Хилли выделяет такого рода аспект в образовательной коммуникации, кото- 
рый играет первостепенную роль в обмене информацией субъектов коммуникации. Рассматривая управленческую функцию образовательной коммуникации, автор вплотную подходит к таким понятиям, как «самоуправление» и «соуправление» [13].

В культурологическом дискурсе партисипация понимается как культура участия или соучастия и предполагает определенное приближение человека, который ранее был только потребителем культурных и социальных смыслов, к позиции производителя [14].

В контексте политологии партисипативность связывается и порой отождествляется с принципом демократии, расширяя его. Осуществление власти народом и в том числе активное включение представителей от общественности в процесс принятия государственных решений, реализации политических и социальных проектов - все это рассматривается «в качестве вида демократической культуры, выступающего важным элементом в распространении демократического режима власти» [15, с. 173]. Такая востребованность партисипативного подхода в общественно-научном пространстве обусловила его дальнейшее распространение в сферу управления, менеджмента. Если говорить о сфере отношений, связанных с образованием, то партисипативность используется как альтернативный. Более современный и эффективный подход «на замену» авторитарному (традиционалистскому). В рамках такого подхода часто декларируется возможность подготовки более взаимно ответственных, настроенных на сотрудничество профессионалов.

Р. Акофф отмечал, что партисипативное управление «означает прямую вовлеченность в процесс планирования всех тех, кого оно непосредственно затрагивает» [7].

В зарубежной литературе отмечается целый ряд особенностей партисипативности как принципа социального управления.

Так, партисипативность связывается:

- с «прямой вовлеченностью» [7] в управленческий процесс (в том числе, проектирования и планирования) тех представителей социальных групп, кого оно непосредственно затрагивает;

- уменьшением трудностей, с которыми обычно связана реализация управленческого проекта, поскольку мероприятия, запланированные в проекте, реализуются исполнителями более эффективно, в том случае если они участвовали в его разработке. Также «благодаря участию выполнение становится неотъемлемой частью процесса проектирования» [5];

- тем, что вовлеченность предопределяет наличие и учет в процессе управления практических рекомендаций участников, которые наиболее заинтересованы в этом. Другим нет до них нужды [8];

- наличием различных точек зрения на решение проблемы, возможностью учета полярных мнений, выработки взвешенных решений и т. д. Чем больше различаются точки зрения на проблему, тем больше альтернативных путей ее решения может быть предложено [16]. В этом заключается еще одно важное преимущество партисипации.

Применительно к проектированию в системе управления учреждением среднего образования определяющим значением «партисипативности» следует считать «вовлечение» как вид социального взаимодействия. Следовательно, можно выделить сущность и специфику партисипативности как вида социально-управленческого взаимодействия. Она заключается в «активном вовлечении и сотрудничестве социальных акторов, в том числе в процессе проектирования» [17], что указывает на инициативность и расширение возможностей акторов в многообразии видов и форм партисипативности как вида социально-управленческого взаимодействия. Поскольку речь может вестись о вовлечении их в процесс разработки управленческих решений. 
Введение этого принципа в практику социального управления и социального проектирования детерминирует «расширение числа субъектов организационного управления» за счет включения заинтересованных лиц - групповых социальных акторов в структуру системы управления» [18].

В случае вовлеченного проектирования (в результате применения принципов и метода партисипации), а также проблемно ориентированного проектирования (в контексте тезаурусного метода) - заинтересованность и компетентность субъектов реализации социального проекта качественно возрастает. К числу конкретных социально-управленческих плюсов от применения такой методологии проектирования применительно к системе управления учреждением среднего образования следует отнести следующие:

- практическая и контекстная ориентированность проекта;

- наличие конкретных, понятных исполнителям цели и задач проекта;

- учёт ситуативного контекста при создании, реализации, контроля над реализацией проекта;

- максимальная степень близости субъекта и объекта управления;

- принципиальные возможности системной интеграции на различных уровнях, например, вовлечение субъектов государственно-частного партнерства, СОНКО, иных социально активных организаций, учредителей.

Необходимо отдельно отметить двойственность, которая характерна для понимания партисипативных проектов различными авторами: они могут быть поняты как проекты, созданные/реализованные с применением принципа партисипативности/созданные и реализованные в логике партисипативности. Иными словами, проект, понимаемый как партисипативный, может быть создан в соучастии с групповыми социальными акторами, заинтересованными в его реализации, или предполагать соучастие в реализации представителей различного рода заинтересованных сообществ.

\section{Выводы}

Очевидно, что в рамках социального проектирования в системе управления учреждением среднего образования «могут быть созданы и реализованы различные типы партисипативных проектов, а также их смешанный тип» [19]. «Все типы партисипативных проектов способствуют формированию среды соучастия» [20, с. 137], вовлечению в систему управления учреждением среднего образования представителей от групп школьной администрации, учителей, учеников, родителей. Сопричастность к управлению, как уже было отмечено ранее, повышает результативность управления. Об этом может свидетельствовать комплексный анализ оценки функционирования системы управления в учреждении среднего образования, согласно соответствующим критериям, а также опыт реализации конкретных партисипативных проектов с сохранением ресурсов/привлечением сторонних ресурсов. Таким образом, в результате выработки и реализации проектов в рамках вышеуказанных принципов вовлеченности, контекстуальности и, соответственно, методологии партисипативного и тезаурусного подходов возможно создание активной среды развития. Значимость и функциональность такого рода среды применительно к учреждениям среднего образования сложно переоценить. Более того, целесообразно говорить о ключевой роли активной образовательно-воспитательной среды развития в повышении успеваемости учащихся как важного индикатора качества среднего образования. 


\section{СПИСОК ЛИТЕРАТУРЫ}

1. Маковкина С.А., Трофимова О.М. Внедрение стандартов управления проектами в государственном и муниципальном управлении // Вопросы управления. - 2016. - № 4 . URL: http://vestnik.uapa.ru/ru/issue/2016/04/7 (дата обращения 05.07.2020).

2. Королева Е.Н., Шептухина Л.И., Шептухин А.Н. Современные стратегии развития городов. - СПб.: Инфо-да, 2017. - 248 с.

3. Steenbergen B. The condition of citizenship. - London: SAGE Publications Ltd, 1994. - $212 \mathrm{p}$.

4. Тощенко Ж.Т. Социология управления. - М.: Юрайт, 2015. - 352 с.

5. Njeru D.K. A research project submitted to the school of business, in partial fulfillment of the requirements of the degree of master of business administration (project management option) of Kenyatta University. URL: https://ir-library.ku.ac.ke/bitstream/handle/123456789/7640/Peter\%20Mathenge.pdf?sequence= 1 \&isAllowed=y (дата обращения 10.12.2020).

6. Arnstein S.N. A ladder of citizen participation // Journal of the American Institute of Planners. - 1969. - № 35 (4). - P. 216-224.

7. Akoff R.L. Creating the corporate future. Plan or be planned for. - New York: Wiley, 1981. - 276 p.

8. A youth participatory project to address STIs and HIV among homeless youth / M.T. Dang, A. Amos, M. Dangerfield, B. Ford, K. Kern, M. Moon // Comprehensive Child and Adolescent Nursing. - 2019. - № 42 (3). P. 222-240. DOI: 10.1080/24694193.2018.1483980.

9. Barasa F., Tubey J. Community participation in project planning, management and implementation: building the foundation for sustainable development // International Journal of Current Research. - 2013. - V. 5. - Iss. 02. - P. 398-401.

10. Dayer C. The project of projecting // Journal of Architectural Education. - 2018. - № 72 (1). - P. 2-3. DOI: 10.1080/10464883.2018.1410635.

11. Деникин А.А. К определению термина «партиципация» в контексте современных художественных практик // Наука телевидения. - 2018. - № 14.1. - С. 43-65.

12. Шкитина Н.С. Верификация концепции эмпатийно-партисипативной подготовки будущего учителя: монография. - Челябинск: Библиотека А. Миллера, 2018. - 418 с.

13. Hilli C. Distance teaching in small rural primary schools: a participatory action research project // Educational Action Research. - 2018. DOI: 10.1080/09650792.2018.1526695.

14. Мороз О. Партиципация как культурная практика. URL: https://postnauka. ru/video/75977 (дата обращения 02.07.2020).

15. Пясецкая И.Ш. Понятийно-терминологический аппарат исследования проблемы формирования партисипативной культуры у будущих менеджеров гостиничного сервиса // Современная высшая школа: инновационный аспект. - 2015. - № 4. - С. 170-176.

16. Kelly J. Towards ethical principles for participatory design practice // CoDesign. - 2018. - № 15 (3). - P. 1-16. DOI: $10.1080 / 15710882.2018 .1502324$.

17. Defining and navigating 'action' in a Participatory Action Research project / B. Guy, T. Feldman, C. Cain, L. Leesman, H. Hood // Educational Action Research. - 2020. - V. 28. - P. 142-153. DOI: 10.1080/09650792.2019.1675524.

18. Clark L.S. Participant or zombie? Exploring the limits of the participatory politics framework through a failed youth participatory action project // The Information Society. - 2016. - № 32 (5). - P. 343-353. DOI: 10.1080/01972243.2016.1212619.

19. О проведении фестиваля молодежных идей (проектов) «Идеи без границ»: постановление администрации города Искитима Новосибирской области от 6 февраля 2014 г. № 176. URL: https://base.garant.ru/7219752/\#friends (дата обращения 08.07.2020).

20. Луков В.А., Туринцева Е.А. Основы социального проектирования и моделирования. - Иркутск: Оттиск, 2017. - 192 с.

Поступила 12.12.2020 2. 


\title{
PARTICIPATIVE DESIGN OF INTEGRATED DEVELOPMENT OF INSTITUTION OF SECONDARY EDUCATION: THEORETICAL-SOCIOLOGICAL ANALYSIS
}

\author{
Elena V. Aleshina, \\ school13@noyabrsk.yanao.ru
}

\begin{abstract}
School no. 13 with in-depth study of subjects of the aesthetic cycle, 40a, Vysotsky street, Noyabrsk, 629803, Russia
\end{abstract}

Elena V. Aleshina, deputy director, School no. 13 with in-depth study of subjects of the aesthetic cycle.

The article considers the concept, specificity and importance of design in the integrated development of secondary education institutions. The author does this from the standpoint of sociological theory, in the discourse of the sociology of management. The concept of project and design is revealed as a formalized activity to determine the problems and plan a number of activities aimed at solving problems within the specified time frame and within certain resources. The typology of projects is briefly described, the forms of projects (service, event), as well as the nature of projects (innovative, supportive) are highlighted. The current trends of the sociological analysis of design are outlined. It is substantiated that participatory design can be aimed at creating active educational environment in a secondary educational institution. Such environment determines the growth in the quality of provision of educational services and their results during a special kind of configured events, with the participation of not only schoolchildren, but also all interested participants in school relations - the administration, parents, NPO, etc. The principle of participatory is cultivated and revealed in the design process. Actors themselves are involved in the design and implementation of the project, in which they are really interested. As a result, the effectiveness of such project increases significantly. And the project itself becomes a catalyst for the formation of team relationships within and between different communities (management, teachers, students, parents, others). It is concluded that participatory design has the potential to form a special type of developmental environment within the framework of a secondary education institution.

Key words: Project, social design, participatory project, active educational environment of development.

\section{REFERENCES}

1. Makovkina S.A., Trofimova O.M. Vnedrenie standartov upravleniya proektami v gosudarstvennom i munitsipalnom upravlenii [Implementation of project management standards in state and municipal government]. Voprosy upravleniya, 2016, no. 4. Available at: http://vestnik.uapa.ru/ru/issue/2016/04/7 (accessed 5 July 2020).

2. Koroleva E.N., Sheptukhina L.I., Sheptukhin A.N. Sovremennye strategii razvitiya gorodov [Modern urban development strategies]. St. Petersburg, Info-da Publ., 2017. 248 p.

3. Steenbergen B. The condition of citizenship. London, SAGE Publ. Ltd, 1994. 212 p.

4. Toshchenko Zh.T. Sotsiologiya upravleniya [Sociology of management]. Moscow, Yurayt Publ., 2015. 352 p.

5. Njeru D.K. A research project submitted to the school of business, in partial fulfillment of the requirements of the degree of master of business administration (project management option) of Kenyatta University. URL: https://ir-library.ku.ac.ke/bitstream/handle/123456789/7640/Peter\%20Mathenge.pdf?sequence= 1\&isAllowed=y (дата обращения 10.12.2020).

6. Arnstein S.N. A Ladder of citizen participation. Journal of the American Institute of Planners, 1969, no. 35 (4), pp. 216-224.

7. Akoff R.L. Creating the corporate future. Plan or be planned for. New York, Wiley, 1981. $276 \mathrm{p}$.

8. Dang M.T., Amos A., Dangerfield M., Ford B., Kern K., Moon M. A youth participatory project to address STIs and HIV among homeless youth. Comprehensive Child and Adolescent Nursing, 2019, no. 42 (3), pp. 222-240. DOI: 10.1080/24694193.2018.1483980. 
9. Barasa F., Tubey J. Community participation in project planning, management and implementation: building the foundation for sustainable development. International Journal of Current Research, 2013, vol. 5, Iss. 02, pp. 398-401.

10. Dayer C. The project of projecting. Journal of Architectural Education, 2018, no. 72 (1), pp. 2-3. DOI: 10.1080/10464883.2018.1410635.

11. Denikin A.A. K opredeleniyu termina «partitsipatsiya» v kontekste sovremennykh khudozhestvennykh praktik [On the definition of the term «participation» in the context of contemporary art practices]. Nauka televideniya, 2018, no. 14.1, pp. 43-65.

12. Shkitina N.S. Verifikatsiya kontseptsii empatiyno-partisipativnoy podgotovki budushchego uchitelya: monografiya [Verification of the concept of empathy-participatory training of the future teacher]. Chelyabinsk, Biblioteka A. Millera Publ., 2018. 418 p.

13. Hilli C. Distance teaching in small rural primary schools: a participatory action research project. Educational Action Research, 2018. DOI: 10.1080/09650792.2018.1526695.

14. Moroz O. Partitsipatsiya kak kulturnaya praktika [Partition as a cultural practice]. 2020. Available at: https://postnauka.ru/video/75977 (accessed 2 July 2020).

15. Pyasetskaya I.Sh. Ponyatiyno-terminologicheskiy apparat issledovaniya problemy formirovaniya partisipativnoy kultury u budushchikh menedzherov gostinichnogo servisa [Conceptual and terminological apparatus for studying the problem of forming a participatory culture in future hotel service managers]. Sovremennaya vysshaya shkola: innovatsionny aspect, 2015, no. 4, pp. 170-176.

16. Kelly J. Towards ethical principles for participatory design practice. CoDesign, 2018, no. 15 (3), pp. 1-16. DOI: $10.1080 / 15710882.2018 .1502324$.

17. Guy B., Feldman T., Cain C., Leesman L., Hood H. Defining and navigating 'action' in a Participatory Action Research project. Educational Action Research, 2020, vol. 28, pp. 142-153. DOI: 10.1080/09650792.2019.1675524.

18. Clark L.S. Participant or zombie? Exploring the limits of the participatory politics framework through a failed youth participatory action project. The Information Society, 2016, no. 32 (5), pp. 343-353. DOI: 10.1080/01972243.2016.1212619.

19. Postanovlenie administratsii goroda Iskitima Novosibirskoy oblasti ot 6 fevralya 2014 g. № 176 O provedenii festivalya molodezhnykh idey (proyektov) «Idei bez granits» [Resolution of the Administration of the city of Iskitim, Novosibirsk region, dated February 6, 2014, No. 176 On holding a festival of youth ideas (projects) «Ideas without borders»]. Available at: https://base.garant.ru/7219752/\#friends (accessed 8 July 2020).

20. Lukov V.A., Turintseva E.A. Osnovy sotsialnogo proektirovaniya i modelirovaniya [Fundamentals of social design and modeling]. Irkutsk, Ottisk Publ., 2017. 192 p.

Received 12 December 2020. 